\title{
Reflections on the 2020 Nobel Memorial Prize Awarded to Paul Milgrom and Robert Wilson
}

\author{
MAARTEN C. W. JANSSEN \\ University of Vienna, National Research University \\ Higher School of Economics (Moscow)
}

The 2020 Nobel Memorial Prize in Economic Sciences has been awarded to Paul Milgrom and Robert Wilson, both at Stanford University, for improvements to auction theory and inventions of new auction formats. As with any award of the Nobel Prize, this year's prize may raise some questions. For example, what is there to learn about auctions that isn't already intuitively known by most economists or practitioners? Or, shouldn't the Prize instead be awarded to research dealing with big and important questions, such as those related to wealth, poverty, inequality, or the environment? Is the importance of auctions on a par with these topics? What important aspects of economic life do we better understand because of the work of the Nobel Prize laureates? The aim of this essay is to try to answer these questions.

Most people, when they think of auctions, probably think of an art auction where rich people come together to determine who will be the new owner of an exclusive piece of art. Bidders bid against each other, the price goes up, and eventually no one wants to compete against the highest bid. At that point, the auction stops, and the winner is announced as the bidder who has submitted the highest bid and who now must pay. This seems to be not so important or complicated that it deserves a Nobel Prize in economics. So, is there more to it or did the Nobel Prize Committee get it terribly wrong this year?

A first part of the answer to this question (and the questions raised above) is that what goes unnoticed in this example is that the auction mechanism is created. Someone has thought that it would be good to organize it and that an auction is probably better than alternatives, such as a lottery, a beauty contest, or a bargaining process with some selected potential buyers. Put into this perspective, the more general problem is

AUTHOR's NoTE: The author would like to thank Theo A. F. Kuipers for comments on an earlier version of this article. 
an allocation problem; namely, how to allocate certain products or resources and what the objectives that the organizer wants to achieve are. Generally, in economics, we think that markets allocate resources; but, in many circumstances, a market simply does not exist, so one must be created. Markets can, however, not be so easily created. There must be buyers (and sellers) who are willing to participate in the market. This is, in a nutshell, the area of market design to which auction theory belongs.

Once the problem is framed in these more general terms, a large set of potential applications suddenly opens up. Who should have the right to use landing or gate slots at busy airports? Who should have the right to produce electricity at a certain time in a certain country? Who should get the right of using certain spectrum frequencies? How should parking places be allocated in the streets of larger cities? Where should gasoline stations be allocated along highways and who should get the right to exploit these locations? Who should get the right to drill for natural resources in a certain designated area and what conditions do we want to impose on these rights? Who should supply a car manufacturer with windshields? Who should get the right to advertise on an internet page? Or how should we allocate emission permits?

Once it is clear that there is a very large set of potential resourceallocation problems to which auction theory may be applied, new issues emerge. First, context is important. In some cases (such as the right to drill for natural resources) uncertainty is important: when I get the right to drill, for example, I still do not know for sure how much of the natural resource I will be able to extract. In other cases (such as rights to landing slots or spectrum usage), a combinatorial element is important: bidders will only have a use for a landing slot at an airport if they have another slot at another airport where they can depart. In still other cases (for example, with electricity and parking slots), timing is an issue. Depending on the context, the allocation problems may have different aspects. Second, objectives may differ from case to case. In some contexts, it may be natural to think that the objective is to generate (or even maximize) revenue; in other contexts, objectives may include fairness, a division of resources over different bidders, or the creation of a competitive market to maximize consumer welfare after the resources are allocated (such as is the case in spectrum auctions). Auctions have the merit of forcing the organizer of the auction to make the objectives of the allocation process transparent and argue why they think that the choice of a particular mechanism (such as an auction) is the best way to reach these objectives. 
The possibility of organizing auctions makes it more difficult (for government authorities) to simply hand over valuable resources to friends or to simply go for historical precedent.

I will now explain that, depending on the context, different complexities arise and that the work of Paul Milgrom and Robert Wilson has proved very fruitful in overcoming these complexities. To do so, and given the space limitations, I present two simple examples that make two of these complexities clear. Milgrom and Wilson's work is, of course, richer than what is depicted in these examples.

\section{WINNER'S CURSE}

Let us first consider an example where uncertainty plays a role. Suppose that, in a classroom, I auction off a jar with euro coins of 1, 2, or 5 eurocents each. Students can inspect the jar and estimate how much money it contains; but they cannot count the number of coins. I ask the students to write down their bid on a piece of paper, and I announce that the jar will be won by the highest bidder and that the winner has to pay their own bid. This auction format is a so-called first-price sealed-bid auction and the auction environment is one of common values: the value of the object is the same for every bidder, but there is uncertainty about what that value is. This is clearly relevant in auctions for the right to extract natural resources; but spectrum auctions or art auctions may also have a common-value flavour.

Suppose that there really is 10 euros in the jar, but different students reach different estimates about the value of the jar. Some students may think there is really only 8 euros in it, whereas more optimistic estimates may say there is 12 euros in the jar. Bidders place a bid below what they think the jar is worth, where the amount they bid less than their value depends (among other things) on how many bidders participate in the auction. Importantly, as bidders are unaware of the estimates of other bidders, they can make their bid conditional only on their own estimate of the jar's worth. Suppose that each bidder bids one euro less than what they think the jar is worth. The bidder with the most optimistic estimate wins and pays, say, 11 euros, which is more than the value of the coins in the jar.

This phenomenon is called the winner's curse, first studied by Robert Wilson (1969). As more optimistic bidders typically bid higher, the winner is typically the bidder with the most optimistic estimate. After the winner is announced, the winner realizes that she was the most optimistic bidder, 
and, knowing that the others were more pessimistic, now believes (after her bid is committed and cannot be changed anymore) that she paid too much for the jar. In a series of articles, Wilson $(1967,1969)$ analysed how to optimally take the winner's curse into account. He showed that the rational response to the winner's curse in a sealed-bid auction is to shade (that is to say, lower) your bid in such a way that the auction generates little revenue. Milgrom (1981), and Milgrom and Weber (1982) extended the pure common-values setting to include common and private values, and showed that open auctions, where bidders get more information during the bidding process, perform better relative to sealed-bid auctions in generating a higher expected revenue. The reason is that other bidders dropping out of the auction gives remaining bidders the opportunity to learn about the estimates of their competitors and to adjust their own estimates. In this way, bidders will be more certain of the true value of the object and will shade their bids much less.

The question of how much information bidders should be allowed to have has been an important consideration in the auction design literature ever since. This is important, not only for generating revenue, but also for the efficiency of the allocation process and for making sure that bidders would like to participate in the auction as they do not want to run unnecessary risks.

\section{Multi-Unit AuCtions}

In many allocation problems, (some) buyers want to acquire either multiple units or nothing. This is clear in the example of airport slots above; but as the present second example will show, it also plays a key role in the spectrum allocation for mobile telecommunications. In these cases, it is clear that multiple objects have to be allocated simultaneously as a bidder may value an object only if she is also able to acquire another object. Consider as an example a country that consists of two regions, $a$ and $b$. A national regulator wants to allocate a frequency band and believes that there may be either a national operator interested in acquiring the right to use the frequency band in both regions, or two regional players (one in $a$ and one in $b$ ) who want to use the frequency for regional usages. In large countries such as the USA, Canada, or Russia, licenses are almost always regionally defined; but, similarly, in a recent 5G auction in Europe, some countries also chose the regional format. ${ }^{1}$ One of the issues Milgrom

\footnotetext{
${ }^{1}$ A similar issue arises if one allocates three objects and some players want to acquire two and others only one.
} 
has addressed, both in his academic papers and in his advisory work, is how to design such a multi-unit auction. Together with Robert Wilson and Preston McAfee, ${ }^{2}$ they provided important input in designing the Simultaneous Multi-Round Auction (SMRA) in 1994 for the Federal Communications Commission (FCC) in the USA to allocate spectrum rights. It was the first practical auction design where multiple units were allocated simultaneously and similar designs have been used in subsequent years in many countries around the globe.

To illustrate the working of the SMRA and to show that it is not satisfactory in all settings, assume for simplicity that the national operator has a value of around 8 for the two licenses together, and a value of 0 for each regional license separately. The value for the regional players is highly uncertain and can be anywhere between 0 and 5 for the license in their region. The regulator decides to allocate regional licenses instead of national licenses to give the regional players a chance to acquire a spectrum that is useful for them. Detailed rules may differ across different SMRAs. One typical set of rules is as follows. In round one, the auctioneer announces a starting price (say, 1 ) for both licenses, $a$ and $b$, and asks the bidders whether they want to acquire the license(s) at that price. ${ }^{3}$ If multiple bidders demand a license, the auctioneer announces one of them as a provisional winner for that round (assigned, for example, at random, or to the bidder who was quicker in expressing demand). For all licenses with excess demand, the auctioneer announces a price for the next round (say, a price of 2) and all bidders who were not provisional winners in the previous round can express their demand at the higher price-one of them is then designated a provisional winning bidder.

This is illustrated in Table 1 below: in round one, the regional players ( $A$ and $B$-with capital letters representing bidders) bid on the license they are interested in and the national player $(N)$ bids on both licenses. Suppose that for license $a$, bidder $N$ is randomly selected as the provisional winning bidder; and for license $b$, bidder $B$ is selected. If the bidders that were not provisional winning bidders come back in the next period at higher prices, then demand remains the same for both licenses, but the provisional winners will now be different.

What is going to happen in round 3? For bidder $B$, the answer is simple. If their willingness to pay is 3 or higher, then they will come back and

\footnotetext{
${ }^{2}$ See the foreword to Milgrom (2004) where some of the early work on FCC auctions is described.

${ }^{3}$ In the initial versions of the SMRA, bidders themselves could bid on the licenses and the auctioneer did not announce clock prices.
} 


\begin{tabular}{c||cccc} 
Round / PRICE & $\begin{array}{c}\text { DEMAND FoR } \\
\text { LICENSE } a\end{array}$ & $\begin{array}{c}\text { DEMAND FOR } \\
\text { LICENSE } b\end{array}$ & $\begin{array}{c}\text { PROVISIONAL } \\
\text { WINNING BIDDER } \\
\text { IN REGION } a\end{array}$ & $\begin{array}{c}\text { PROVISIONAL } \\
\text { WinNING BIDDER } \\
\text { IN REGION } b\end{array}$ \\
\hline \hline 1 & $A, N$ & $B, N$ & $N$ & $B$ \\
2 & $A, N$ & $B, N$ & $A$ & $N$ \\
3 & $\ldots$ & $\ldots$ & $\ldots$ & $\ldots$
\end{tabular}

Table 1: An illustration of the SMRA.

bid on license $b$; otherwise, they will drop out. But will bidder $N$ bid again on license $a$ ? Both options (of continuing to bid, or not) are associated with considerable risk. If bidder $N$ does not bid on $a$, they would hope that they are overbid on $b$ in round 3 , so that they do not acquire only one license (whose value for $N$ is zero). But this is not known to $N$. On the other hand, if bidder $N$ does bid on $a$, it may be that both bidder $B$ will come back in round 3 and bidder $A$ will come back in round 4 . In that case, $N$ will only be able to acquire both blocks for a total price of at least 9 , which is higher than $N$ 's value. This problem cannot be resolved easily and is due to the fact that bidder $N$ only values a full bundle, but in an SMRA they may end up with only part of the bundle. This is called the exposure problem, and it makes multi-unit auctions much more complicated than single-unit auctions. Also, bidders may prefer not to participate in the auction in the first place if they fear that the exposure problem is a real risk. This potential non-participation may create significant inefficiencies.

The so-called combinatorial clock auction, invented by Paul Milgrom together with Larry Ausubel and Peter Cramton (Ausubel, Cramton, and Milgrom 2006), addresses this problem. In this auction format, at each round price, bidders announce which licenses they would like to get. This demand is interpreted as an all-or-nothing demand so that if bidder $N$ says that, at a price of 2, they demand both licenses, they either get both of them or nothing. The combinatorial clock auction has, however, problems of its own, ${ }^{4}$ and currently there is no auction design that works efficiently in all possible multi-object contexts. The work by Paul Milgrom has, however, been important in illuminating the different issues that are relevant for auctioning multiple objects and in sketching the circumstances under which a particular auction design is expected to do best.

\footnotetext{
${ }^{4}$ For a more detailed treatment of the combinatorial clock auction and some of its problems, see Levin and Skrzypacz (2016), and Janssen and Kasberger (2019).
} 


\section{CONCLUDING}

In conclusion, let me go back to the questions I started out with. First, it should be clear by now that, because of the vast number of potential applications in very different areas, it is important to have a better understanding of how different possible auction formats may work and when they can be applied. Efficiency gains that can be obtained through auctions are relevant in many different economic and non-economic situations. If governments use auctions to allocate public assets, they can have a variety of objectives. If they aim at maximizing revenue, then the proceeds can be used (and many governments do use them) for many different social goals.

Second, by discussing two important issues in auction design, I have explained that once one goes beyond standard auctions, such as antique auctions, there are important issues that need to be addressed. These issues are non-trivial and deserve careful analysis. To outsiders, these issues may appear to be 'details'; but often, in auction design, the devil is in the details, and if the details are not properly dealt with, the whole auction design may fail and the goals may not be realized.

Finally, we may ask whether because of the work of this year's laureates we now understand better some aspects of economic life? The answer to this question is more subtle, I think. In many auctions, the bidding data is not publicly available, and even if they are available, we typically do not know the valuations of different bidders and, therefore, cannot investigate why they bid the way they did. The assumptions underlying the theory-namely, that bidders have a clear valuation for the objects, that they only care about what they acquire and at what price, and, therefore, that these valuations typically do not depend on who else wins part of the objects and what others have to pay-cannot be verified. Often, also, we do not know the counterfactual, that is, what the (auction) outcome would have been had a different format been chosen. The success of auction theory seems therefore driven not by being able to better predict behaviour or explain what happens in a particular auction. ${ }^{5}$ Rather, success here seems to be related to what Alvin Roth said already some time ago in The Economic Journal: "the real test of our success will be [...] how well we can bring this knowledge to bear on practical questions of microeconomic engineering" (Roth 1991, 113). More and more, it seems that a proper assessment of economics as a science should not only rely

\footnotetext{
${ }^{5}$ Progress in auction design seems to have common properties with what Kuipers (forthcoming) describes as progress in concept explication.
} 
on whether it is able to make better predictions, but also on how it is used to design new mechanisms to allocate resources. Together with the 2007 and 2012 Nobel Prizes for mechanism design (to Leonid Hurwicz, Eric Maskin, and Roger Myerson) and market design (to Alvin Roth and Lloyd Shapley), respectively, this year's award testifies to this shift in the economics profession.

\section{REFERENCES}

Ausubel, Lawrence M., Peter Cramton, and Paul Milgrom. 2006. "The Clock-Proxy Auction: A Practical Combinatorial Auction Design." In Combinatorial Auctions, edited by Peter Cramton, Yoav Shoham, and Richard Steinberg, 115-138. Cambridge, MA: The MIT Press.

Janssen, Maarten C. W., and Bernhard Kasberger. 2019. "On the Clock of the Combinatorial Clock Auction.” Theoretical Economics 14 (4): 1271-1307.

Kuipers, Theo A. F. Forthcoming. "The Logic of Qualitative Progress in Nomic, Design, and Explicative Research." In Current Trends in Philosophy of Science: A Prospective for the Near Future, edited by Wenceslao J. Gonzalez. Cham: Springer.

Levin, Jonathan, and Andrzej Skrzypacz. 2016. "Properties of the Combinatorial Clock Auction.” American Economic Review 106 (9): 2528-2551.

Milgrom, Paul R. 1981. "Rational Expectations, Information Acquisition, and Competitive Bidding." Econometrica 49 (4): 921-943.

Milgrom, Paul R. 2004. Putting Auction Theory to Work. Cambridge: Cambridge University Press.

Milgrom, Paul R., and Robert J. Weber. 1982. "A Theory of Auctions and Competitive Bidding." Econometrica 50 (5): 1089-1122.

Roth, Alvin E. 1991. "Game Theory as a Part of Empirical Economics." The Economic Journal 101 (404): 107-114.

Wilson, Robert B. 1967. "Competitive Bidding with Asymmetrical Information." Management Science 13 (11): 816-820.

Wilson, Robert B. 1969. "Competitive Bidding with Disparate Information." Management Science 15 (7): 446-448.

Maarten C. W. Janssen is Professor of Microeconomics at the University of Vienna. Before joining Vienna he was a professor of Microeconomics at Erasmus University Rotterdam and director of the Tinbergen Institute. His main academic research area is the theory of industrial organization, where he is known for his work on consumer search and auctions. He created the Vienna Graduate School of Economics, is an elected foreign member of The Royal Holland Society of Sciences and Humanities, a fellow of the Centre for Economic Policy Research (London), and holds an honorary doctorate from the Higher School of Economics (Moscow). He has been awarded the Distinguished Visiting Austrian Chair Professor at Stanford University for the year 2022.

Contact e-mail: <maarten.janssen@univie.ac.at> 